\title{
Knowledge and Practice of Sectors of Health-Care Workers towards Universal Precautions in Baghdad Teaching Hospital
}

\author{
Shayma S. Ali
}

MBCHB, IFCMS/ FM

Abstract:

J Fac Med Baghdad 2015; Vol.57, No.1 Received Sept.2014 Accepted Dec.2014

Background: Universal precautions, as defined by centers for disease control (CDC), are a set of precautions designed to prevent transmission of human immunodeficiency virus, hepatitis B virus, and other blood borne pathogens when providing first aid or health care .

Objectives: To measure knowledge of and practice towards universal precautions among healthcare workers (apart from doctors) in Baghdad Teaching Hospital .

Material and methods: A cross-sectional study was conducted during the period of two months from 26th of February to the end of April 2007 in Baghdad Teaching Hospital / Medical City ,Baghdad to assess the knowledge and practice of 110 health care workers towards the use of universal precautions in their daily work and to assess the effect of different factors on both knowledge and practice (including :age, years of experience gender, level of education, occupation and hearing about universal precautions ) .

Results: The study showed that $(52.7 \%)$ had heard about universal precautions with an overall low understanding of precautions except concerning disposal of sharp instruments, use of protective equipment and clean of spilled blood.Health workers showed difficulty to distinguish deep body fluids to which universal precautions should be applied from body secretions to which they are not applied (saliva and sweat). Good practices were reported regarding hand washing, disposal of needles and sharps,and gloves, masks and gown usage. This study showed that hearing about universal precautions had no positive effect on knowledge as those who had heard about universal precautions had mean knowledge score of (5.9) from total score of (10) which is lower than those who never heard with mean knowledge score of (6.1), in contrast to practice score which was higher in those who heard about universal precautions (8.4) than those who never heard (8), from total score of (10).

Conclusion: universal precautions were not only insufficiently but also selectively understood and applied so great work should be done in form of pre- and in-service education and training programs to the staff with good supply of protective equipment to implement universal precautions on scientific and practical basis in near future.

Keywords: Universal Precautions, knowledge, practice, Healthcare workers, Blood borne pathogens ,centers for disease control (CDC).

\section{Introduction:}

Since medical history \& examination cannot reliably identify all patients with human immune deficiency virus (HIV) and other blood borne pathogens, the United States Centers for Disease Control (CDC) has proposed a series of procedures that health care workers (HCWs) should use with all patients ,"Universal Precautions" are designed to prevent them being exposed to blood \&body fluids by applying the basic principles of infection control through hand washing, utilization of appropriate protective barriers such as gloves, mask ,gown and eyewear, and safe handling of needles, so HCWs should consider all patient as potentially infected with HIV and/or blood borne pathogens [1],[2].Universal Precautions (UP) are important since the transmission of blood borne pathogens from patient to HCWs via occupational exposure has been well known for many years[3 ] .

This importance include the aspect of patient protection as well since that unsafe injection practices, or contamination

*Ministry of health /Baghdad Al-Russafa health directorate.

Email:Salmanshyma@yahoo.com of multiple-dose medication vials, lead to patient to patient transmission of blood borne pathogens thus all HCWs should adhere to the recommended universal precautions and fundamental infection control principles and appropriate aseptic techniques [4]. HCWs working in hospitals frequently provide care to patients whose hepatitis B virus (HBV) or HIV status is unknown. The risk of HBV after a known occupational exposure is about $25 \%$ furthermore there is a 0.3 0.5 occupational risk of infection with HIV after percutaneous exposure to HIV contaminated blood [5]. Since overuse of universal Precautions will make the work of HCWs so difficult .Body fluids to which universal Precautions should be applied are : 1- Blood and other body fluids containing visible blood. 2- Semen and vaginal secretions 3- Tissues, cerebrospinal fluid (CSF), synovial, pleural, peritoneal, pericardial, and amniotic fluids. Universal precautions are not applied to 1-feces, urine, nasal secretions, sputum, sweat, tears, saliva and vomits unless these fluids contain visible blood . 2-Human breast milk [6] [7]. Under universal Precautions, the CDC put many guidelines 
health care workers should follow to protect themselves These guidelines include :I / Hand washing II / Use of protective barriers including : gowns or aprons , masks and protective eye wears, gloves. III/ Safe handling and Safe disposal of sharps: IV/ Waste management.[1,2,6,8,9,10] .Hepatitis $B$ virus is a well-known occupational hazard of health care workers and they are considered to be at a substantial risk for acquiring or transmitting the virus because of the occupational contact with blood, blood products and other body fluids [11]. In Iraq viral hepatitis is endemic, the prevalence of hepatitis B surface antigen (HBSAg) is 2-3\% in normal population\& slightly higher among health professionals, hepatitis $\mathrm{C}$ is of low endemicity $(0.5 \%)$, for HIV Iraq still among the low prevalence countries for HIV/AIDS[12]. The majority of HIV infection in Iraq has been reported among young men with hemophilia through infected blood products and the main mode of transmission among reported AIDS cases $(86.1 \%)$ via blood products[13].

\section{Patients and Methods:}

A cross-sectional study was conducted during the period of two months from 26th of February to the end of April 2007 in Baghdad Teaching Hospital/Medical City ,Baghdad, to assess the knowledge and practice towards universal precautions of 110 HCWs including nurses, nurse officers, midwives, laboratory workers \& operating room staff.Doctors were not included in the study. The sample was chosen randomly from all Baghdad Teaching Hospital wards, renal dialysis unit ,delivery room, operating theatres \& laboratories, constitute (40\%) of total HCWs in the hospital which were 160 participants out of total 400 . Finally only $110(27.5 \%)$ participated and 50 questionnaires were returned unanswered or missed .Self - administered questionnaire, consisting of 3 parts ,Part I : collected demographic data, Part II : asked respondents if they had heard about universal precautions (U.P.) and then measured knowledge of U.P. with 10 statements scored "true" or " false", maximum score of 10 . Part III : assessed their practice towards U.P. in 8 questions about use of protective devices, disposal of sharps $\&$ decontamination of spills $\&$ used articles(scored "agree" or "disagree")with maximum score of 8 modified to 10.The questionnaire was adapted from Eastern Mediterranean Health Journal, volume 12(s) 2006, from a study of Motamed N. et al, about knowledge and practice of HCWs \& medical students towards U.P. in hospitals in Mazandaran province in Iran [14] .The content validity and reliability of the questionnaire was assessed by expert counsel in preventive medicine from Iraqi board for medical specializations. The data was statistically analyzed using SPSS, version 13. Frequency distribution for selected variables was done first. The statistical significance of difference in mean of a discrete , quantitative variable(scored based on counts ) was tested by non-parametric tests; i.e the difference between 2 groups was assessed by Mann-Whitney test, while between more than 2 groups the Kruskall-Wallis test was used, and Chi-square test was used for statistical significance analysis. The strength ,direction and statistical significance of linear correlation between 2 quantitative variables was tested by spearman's rank correlation coefficient .P value of less than 0.05 level of significance was considered statistically significant.

\section{Results:}

Demographic data: Of 160 questionnaires distributed 110 (68.75\%) were completed and 50 (31.25\%) were unanswered or missed. $52.7 \%$ of the participants had heard about universal precautions. Among the staff respondents the majority (44.5\%) were 30-39 years old ,males constitutes $55.5 \%$ and 50\% of them had 6-15 years of experience and only $32.7 \%$ had 16 years or more, for level of education those who graduated from medical technical institution constitute $43.6 \%$ and only $16.4 \%$ had college degree . ( table 1 ) .Knowledge of universal precautions: most of the staff answered correctly to items related to disposal of sharps $(94.5 \%)$, workers with non-intact skin not come in direct patient care until condition resolved(83.6\%), applying universal precautions to all persons regardless their infectious status(81.8\%). They had obvious misconception regarding use of universal precaution as in situations that lead to contact with saliva(90.9\%), decontamination of devices such as manometer (used for skin contact only) by washing with usual detergents is insufficient $(75.5 \%)$ and isolation is necessary in patient with blood born infections $(67.3 \%)$ (table2). Practice towards universal precautions: concerning the use of protective devices ,the majority of respondents agreed on the practice of wearing gloves, gown and eye wear when they were exposed to deep body fluids or blood products, good practice noted on safe disposal of needles and sharps (94.5\%) and on hand washing for 5 minutes is the first step after contact with infective materials $(88.2 \%)$. While in applying universal precautions in situations that might lead to contact with sweat here only (24.5\%) answered correctly .(Table2)

Correlation between knowledge score, practice score and some demographic data: the correlations between knowledge score and practice score and the correlation between each of them with other variables using spearman's rank correlation coefficient showed that no correlation between knowledge score and practice score (-0.062). For the age in years, it has no correlation with knowledge score $(-0.05)$ but has significant positive correlation with practice score $(0.192)$. For years of experience, again it has no correlation with knowledge score but has a positive significant correlation with both practice score $(0.213)$ and age in years( 0.684$)$.For level of education ,it has a positive correlation with both knowledge score and practice score which was statistically not significant, but shows a negative statistically significant correlations with both age in years $(-0.380)$ and years of experience $(-0.249)$. (table3)Using Mann-Whitney test, the Kruskall-Wallis test, it was found regarding mean knowledge score no significant difference among different demographic groups, for practice significant difference ( $\mathrm{p}$ less than 0.05 ) in mean practice score was found between different age groups being higher in those (30-39) and (40+) and lower in (less than 30), also significant 
differences found among years of experience categories being higher in (6-15)and (16+) but lower in (1-5) years.

Tables:Table 1:The distribution of the participants according to the demographic characters.

\begin{tabular}{|c|c|c|}
\hline & $\mathbf{N}$ & $\%$ \\
\hline \multicolumn{3}{|l|}{ Age groups (years) } \\
\hline$<30$ & 36 & 32.7 \\
\hline 30-39 & 49 & 44.5 \\
\hline $40+$ & 25 & 22.7 \\
\hline \multicolumn{3}{|l|}{ Gender } \\
\hline Female & 49 & 44.5 \\
\hline Male & 61 & 55.5 \\
\hline \multicolumn{3}{|l|}{ Years of experience-categories } \\
\hline$(1-5)$ & 19 & 17.3 \\
\hline$(6-15)$ & 55 & 50 \\
\hline $16+$ & 36 & 32.7 \\
\hline \multicolumn{3}{|l|}{ Level of education } \\
\hline Primary to intermediate school & 14 & 12.7 \\
\hline Secondary school & 30 & 27.3 \\
\hline Medical institution & 48 & 43.6 \\
\hline College & 18 & 16.4 \\
\hline \multicolumn{3}{|l|}{ Occupation } \\
\hline Nurse & 53 & 48.2 \\
\hline Midwife & 18 & 16.4 \\
\hline Nurse officer & 5 & 4.5 \\
\hline Lab. Personnel & 23 & 20.9 \\
\hline Operating room staff & 11 & 10 \\
\hline \multicolumn{3}{|c|}{ Heard about UP (Universal Precautions) } \\
\hline No & 52 & 47.3 \\
\hline Yes & 58 & 52.7 \\
\hline Total & 110 & 100 \\
\hline
\end{tabular}

$\mathrm{N}=$ total number of respondents.

Table 2:knowledge and practice of health care workers in numbers and percentages.

\begin{tabular}{lll}
\hline$(\mathrm{n}=110)$ & $\mathrm{N}$ & $\%$ \\
\hline Correct knowledge & & \\
\hline
\end{tabular}

UP should be applied to all persons regardless of infectious status (True)

$90 \quad 81.8$

For decontamination of devices such as manometer (used for skin contact only) washing with usual detergents is enough (True)

Subcutaneous injuries during intravenous injections are the most common cause of occupational infections (True)

UP are not necessary in situations that might lead to contact with saliva (True)

Workers with non intact skin should not be involved in direct patient care until the condition is resolved (True)

Blood spills should be cleaned up promptly with

sodium hypochloride (True)

(10.0.

$10 \quad 9.1$

$92 \quad 83.6$

$81 \quad 73.6$

Misconceptions

UP are applied to patients with HIV\&HBV only . $\quad 32 \quad 29.1$

\begin{tabular}{lllll}
\hline Isolation is necessary for patients with blood-borne & 74 & $\mathbf{6 7 . 3}$
\end{tabular}
infection . \begin{tabular}{l}
$\begin{array}{l}\text { Used needles can be recapped after giving an } \\
\text { injection. }\end{array}$ \\
\hline
\end{tabular}

\begin{tabular}{llll}
\hline Availability of an effective anti-HCV vaccine . & 51 & 46.4
\end{tabular}

Good practice

Assuming that blood and all body fluids of patients are infectious (True)

Wearing mask, gown and eye wear if procedures and patient care activities are likely to cause splashing of blood and deep body fluids (True)

Disposing used needles into a closed box after injection (True)

Wearing gloves as the first step in cleaning surfaces contaminated with blood or other bloody body fluids (True)

Washing with soap and water for 5 minutes is my 1 st step after contact with infective material (True)

Applying UP in situations that might lead to contact with sweat (False)

Having a wound, gloves are used before caring for patients (True)

Applying UP in situations that might lead to contact with vaginal discharge (True)

$\mathrm{N}=$ total number of respondents.

$\mathrm{HCV}=$ hepatitis $\mathrm{C}$ virus ; $\mathrm{HIV}=$ human immunodeficiency virus ; $\mathrm{HBV}=$ hepatitis B virus . 
Table 3 :The correlations between knowledge score, practice score and other demographic characters.

\begin{tabular}{ccccc}
\hline $\begin{array}{c}\text { Correlation } \\
\text { Coefficient }\end{array}$ & $\begin{array}{c}\text { Knowledge } \\
\text { score }\end{array}$ & $\begin{array}{c}\text { Practice } \\
\text { score }\end{array}$ & $\begin{array}{c}\text { Age in } \\
\text { years }\end{array}$ & $\begin{array}{c}\text { Years of } \\
\text { experience }\end{array}$ \\
\hline Practice score & $-\mathbf{0 . 0 6 2}$ & & & \\
\hline Age in years & -0.05 & $.192(*)$ & & \\
\hline $\begin{array}{c}\text { Years of } \\
\text { experience }\end{array}$ & $-\mathbf{0 . 0 6 9}$ & $.213(*)$ & $.684(* *)$ & \\
\hline $\begin{array}{c}\text { Level of } \\
\text { education }\end{array}$ & $\mathbf{0 . 1 8 6}$ & $\mathbf{0 . 1 6 5}$ & $-.380(* *)$ & $-.249(* *)$ \\
\hline $\left.\begin{array}{c}* \\
(* *)\end{array}\right)=\mathrm{P}<0.05$ & & & & \\
\end{tabular}

\section{Discussion:}

HCWs in Baghdad Teaching Hospital, despite their good or accepted percentages of correct answers to questions assessing their practice especially in wearing protective devices as masks, gowns and gloves, in disposal of sharps(as needles \&scalpels) and using universal precautions in case of contact with vaginal discharge and in cleaning of blood spills ,but one might notice that HCWs actually could not differentiate between their daily routine precautions they used to apply to protect themselves against infection and the internationally sound recommendations of U.P., their purpose , recommendations and in which condition they are necessary and in which they are not. This appears clear from their (HCWs) answers to selected questions assessing their knowledge or practice and might be explained by lack of or incomplete implementation of U.P. in their hospital which was enforced by that only $52.7 \%$ of them had heard about U.P. Although implementation of universal precautions does not eliminate the need for other isolation precautions as droplets precaution for influenza, airborne isolation for pulmonary TB [15], it eliminates the need for isolation of patients who have or suspected to have blood borne infections (blood and body fluids precautions) [1]. In the study, the participants showed (67.5\%) misconception regarding if isolation is necessary for patients with blood borne infections, this ,again, reflect the low understanding of universal precautions. The study of Motamed N. et al also showed low understanding of HCWs and medical students towards U.P. in two hospitals in Mazanderan province in Iran except concerning disposal of sharps, contact with vaginal discharge, use of masks and gowns and cleaning of blood spills [14]. Although U.P. are effective method in reducing the risk of occupational exposures among physicians and HCWs in medical series [ 16], only (52.7\%) of participants have ever heard about universal precautions. which is ,in fact, low and reflects the poor concentration on universal precautions. in pre-service and in-service education programs to health personnel .One of the important finding in the study is the lack of correlation between knowledge and practice among HCWs. This might be explained on many bases as : The poor role of the infection control committee that supervise and follow the practice of $\mathrm{HCW}$ regarding implementation of infection control procedures and plan for in -service training programs in Baghdad Teaching Hospital, the limited availability of many important protective equipment as gowns, masks, eyewear and even gloves to be used by HCWs. at time of study and that some of HCWs had good knowledge but poor practice due to their carelessness, others had poor knowledge but good practice as they used to follow certain infection control guides as a routine without real understanding of their purpose or when to be used scientifically which may lead to overuse of some precautions as use of U.P. in case of contact with saliva or sweat .Askarian et al showed in their study, an acceptable knowledge but poor practice regarding standard precautions (which include U.P. ) among Iranian nurses in Shiraz Teaching Hospital is due to inadequate supply of personnel protective equipments, improper disposal of medical wastes and lack of effective needle disposal system [17]. Other finding was that age shows no correlation with knowledge but positive statistically significant correlation with practice which may be due to increase experience with increasing age that lead to improve practice. This is enforced by positive statistically significant correlation of years of experience with score of practice, but again no correlation with knowledge .In their study, Kabbash et al showed that years of experience had no influence on knowledge of the studied nurses regarding HIV infection, HBV infection and U.P. used to protect staff against. They thought that this could be due to lack of regular system of in-service orientation courses about recent scientific information [18], which could be the same explanation in our study .In the current study the level of education had a positive, although weak correlation with knowledge and practice so, the higher the education level of the health personnel, the better his knowledge and performance regarding infection control ,but education level had a negative statistically significant correlation with age and years of experience this might be explained on the base that the majority of those with higher education ( medical institutions and colleges ) are of younger age and less experience, while the majority of those with older age and hence more experience are of lower educational level ( primary to intermediate schools ). Also, it was found that the highest mean knowledge score was among HCWs with college degree of education ( 6.6 ), and the knowledge score was highest among laboratory personnel since high percentage of them $(44.4 \%)$ was of college degree and ( $50 \%)$ of medical institutions ; i.e higher level of education .This might be explained that those with higher education received more information on infection control in their study courses. Also it was found that the highest practice score was among older age group and those with more experience which was statistically significant $(\mathrm{P}<0.05)$, which may reflect the importance of experience and in-service training programs in improving practice.There was a narrow difference in mean practice score 
between those who heard (8.4) and those who never heard (8) about U.P. that might reflect that even good practice may be part of routine work and not a part of systematic application of universal precautions in hospitals .Regarding practice, Aisien AO. ,showed in his study that there was poor adherence of HCWs to universal precautions which was attributed to lack of knowledge and availability of materials in $48 \%$ of HCW.s and $60 \%$ respectively [ 19$]$.

\section{Conclusion:}

From this study we can conclude the following :The included HCWs in the study in Baghdad Teaching Hospital had an overall low understanding of universal precautions . Good practice in certain fields as wearing protective equipment, safe disposal of sharps and others was just part of routine work and not due to implementation of real U.P. based on scientific internationally sound basis .Absence of scientific pre- and inservice education and training programs regarding universal precautions to prepare a qualified, well trained personnel that can protect themselves as well as the patients against blood borne pathogens, as mere information about safe practices alone are insufficient to achieve this goal .

Hearing about U.P. does not mean a good knowledge about them.

\section{References :}

1. Center for Disease Control and Prevention (CDC). Universal Precautions for Prevention of Transmission of HIV and Other Blood borne Infection. Fact sheet, 1996.

2.Center for Disease Control and Prevention(CDC) . Recommendations for prevention HIV transmission in healthcare setting. Morbidity and mortality weekly report (MMWR) supplements, 1987,36 (SU02).

3. Kahhaleh J.G. and Jurjus A.R. Adherence to universal precautions among laboratory personnel in Lebanon. Eastern Mediterranean health journal, 2005;11:929-943

4. Center for Disease Control and Prevention(CDC) .Transmission of Hepatitis $B$ and $C$ Viruses in outpatient setting .New York, Oklahoma, and Nebrasha,2000-2002. MMWR, 2003;52(38):901-906.

5. ChinJE.Control of Communicable Disease manual,17thed. Washington,American Public Health Association ; 2000 :1-9. 6. (CDC) . Universal Precautions for Prevention of Transmission of HIV, Hepatitis B virus and other bloodborne pathogens in healthcare settings. MMWR,1988;37(24) : 377388 .

7. Center for Disease Control and Prevention (CDC). Updated CDC Recommendation for Management of hepatitis B Virus in Infected Health-Care Providers and Students .

MMWR,2012 July 6;61:5-6.

8. WHO Report on consultation and prevention of HIV and HBV transmission in healthcare setting ,April 1991:1-6.

9 . Jane D. et al .Guidelines for isolation precautions : Preventing transmission of infectious agents in health-care settings.CDC,2007:49-54.
10. F.Cindy. Universal Precautions Health Article. Gale ,Detroid. Gale Encyclopedia of Nursing and Allied Health, 2002.Accessed through : www.healthline.com/galecontent/ universal_precautions_1.

11.Othman M, Saleh A, Shabila P. Knowledge About Hepatitis B Infection Among Medical Students In Erbil City ,Iraq. European Scientific Journal ,2013 December; 3 :

299-305

12. Alwan A. Health in Iraq. Baghdad, MOH ,2004 : 27-28.

13. World Health Organization (WHO). Epidemiological fact sheets on HIVIAIDS and sexually transmitted infections update ,2004: 2 .(IVSL)

14. Motamed N. et al .Knowledge and Practice of healthcare worker and medical students towards universal precautions In hospitals In Mazandaran province .Eastern Mediterranean Health Journal ,2006; 12(5): 653-662.

15.Garner JS .Guidelines for Isolation Precautions in hospitals.Hospital Infection Control Advisory Committee. Infection control hospital epidemiol ,1996;17:53-80.(IVSL)

16. Wong ES. et al .Are universal precautions effective in reducing the number of occupational exposure among healthcare workers ?.Journal of American Medical Association, 1991;265:1123-8

17. Askarian M. et al Knowledge, practice and attitude among Iranian nurses, midwives and students regarding standard isolation precautions. Infection control and hospital epidemiology, 2007 ;28:241-244

18. Kabbash IA. et al .Risk perception and precautions taken by healthcare workers for HIV infection in hemodialysis units in Egypt. Eastern Mediterranean health journal, 2007;13: 392-407.

19. Aisien AO. Universal precautions and attitudes towards PLWHA in Benin-city, Nigeria .Nigerian Journal of clinical practice, $2005 ; 8: 47-82$. 